九州大学学術情報リポジトリ

Kyushu University Institutional Repository

\title{
Experimental Study of NACA 0012 Airfoil with Slanted Drills Through the Body
}

Nogib Anwar Zafi

Department of Aeronautical Engineering, Military Institute of Science \& Technology

Md. Afjal Hossain

Department of Aeronautical Engineering, Military Institute of Science \& Technology

Md. Taohid Islam Mim

Department of Aeronautical Engineering, Military Institute of Science \& Technology

https://doi.org/10.5109/4102500

出版情報: Proceedings of International Exchange and Innovation Conference on Engineering \& Sciences (IEICES). 6, pp. 258-263, 2020-10-22. Interdisciplinary Graduate School of Engineering Sciences, Kyushu University バージョン：

権利関係 : 


\title{
Experimental Study of NACA 0012 Airfoil with Slanted Drills Through the Body
}

\author{
Nogib Anwar Zafi, Md. Afjal Hossain, Md. Taohid Islam Mim \\ Department of Aeronautical Engineering, Military Institute of Science \& Technology, Bangladesh \\ Corresponding author email: anwar.zafi@gmail.com
}

\begin{abstract}
The objective of this paper is to present a comparative study of aerodynamic behavior between a conventional and a modified NACA 0012 airfoil. The modified airfoil has slanted drills through its body where the holes were made along the span at 25\%,50\% and 75\% of the total chord length of the airfoil. Each row consisted of 4 through holes slanted at $45^{\circ}$. The experiment was carried out at four different Reynolds Numbers in between $1.03 e^{5}$ to $2.58 e^{5}$ and readings were taken at $0^{\circ}$ to $20^{\circ}$ angle of attack and validated by numerical simulation. It was observed that the coefficient of lift for both the airfoils were almost the same up to $12^{\circ}$ angle of attack but the drilled airfoil shows more coefficient of lift than the conventional one at higher angle of attacks. The coefficient of drag remained almost similar for both the airfoils at every condition.
\end{abstract}

Keywords: airfoil, slanted holes, coefficient of lift, coefficient of drag

\section{INTRODUCTION}

Passive flow control is a great way to improve aerodynamic behavior of a wing by delaying boundary layer separation delay. To achieve this objective, different modifications are performed on wings to manipulate the airflow which helps to increase lift, reduce drag, delay stall or increase overall aerodynamic efficiency sometimes. Passive flow control is becoming an interesting research study field as this technique doesn't require any external power to manipulate the flow. Xie et al. [1] investigated a passive flow control technique called split blade on S809 airfoil both numerically and experimentally. In this experiment a straight slot was created connecting the upper and lower surface of S809 airfoil which enables the flow from the pressure side to go through the suction side of the airfoil. At Reynolds number of $10^{6}$, there was a slight improvement in life coefficient at 20 degree AOA. Ni et al. [2] studied the effect of internal slots combined with leading edge tubercles both experimentally and numerically. At Reynolds number of $10^{5}$.The internal slot combined with smaller leading edge tubercles improve both coefficient of lift and drag in the range of $10^{\circ}-20^{\circ}$ AOA and internal slot combined with bigger leading edge tubercles improve the aerodynamic efficiency in the range of $20^{\circ}-30^{\circ}$ AOA. Sumesh et al. [3] showed a study on the effect of $3 \mathrm{~mm}$ holes adjacent to the thin airfoil leading edge on the noise characteristics. Modified airfoil with holes reduced lower frequency noise $(<3.5 \mathrm{KHz})$ up to $5 \mathrm{~dB}$. This method is ineffective for higher frequency noise. Wong et al. [4] investigated the effect of spanwise blowing on NACA 0012 airfoil. It was found out that the coefficient of lift gets increased when steady blowing occurs especially at $25 \%$ of the chord line. Due to the unsteady blowing, the stall angle was delayed from $10^{\circ}$ to $11^{\circ}$ due to the reattachment of flows which also increased the coefficient of lift.

\section{EXPERIMENT}

The experiment was focused on the data collected with the help of a low speed subsonic wind tunnel. All the readings were taken by using Versatile Data Acquisition System (VDAS).

\subsection{Modeling:}

In order to perform this experiment, a NACA 0012 airfoil with a span of $300 \mathrm{~mm}$ and chord of $150 \mathrm{~mm}$ was modeled and then fabricated with balsa wood. This wooden prototype was used for investigating lift-drag characteristic of a conventional airfoil shown in Fig. 1.

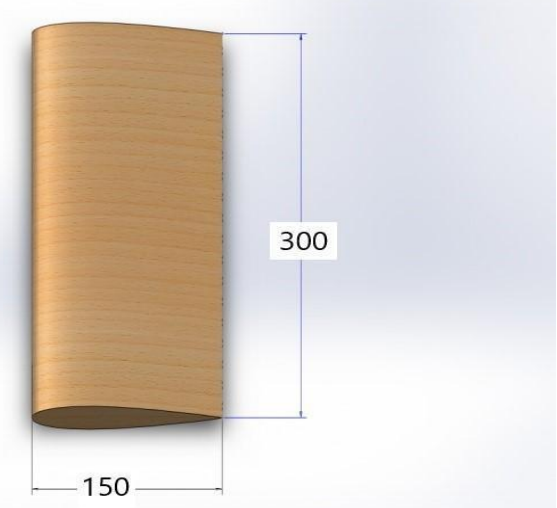

Fig. 1: Conventional Wing Section with NACA 0012 airfoil

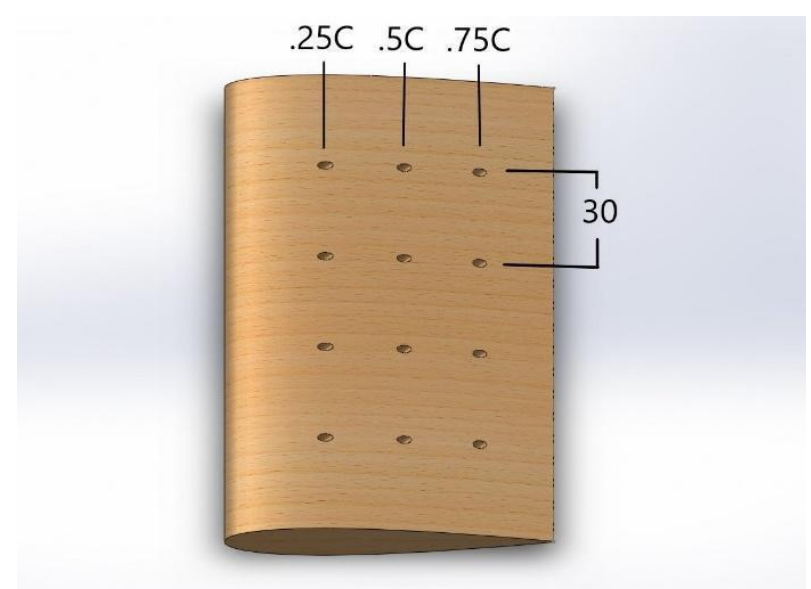

Fig. 2: Modified Wing Section with NACA 0012 Airfoil 
Another identical wooden prototype of NACA 0012 airfoil shown in Fig. 2, was fabricated and thereby modified with drilled holes connecting pressure surface and suction surface. Four holes were drilled span wise at 25,50 and 75 percent chord $(.25 \mathrm{C}, .5 \mathrm{C}$ and $.75 \mathrm{C})$.

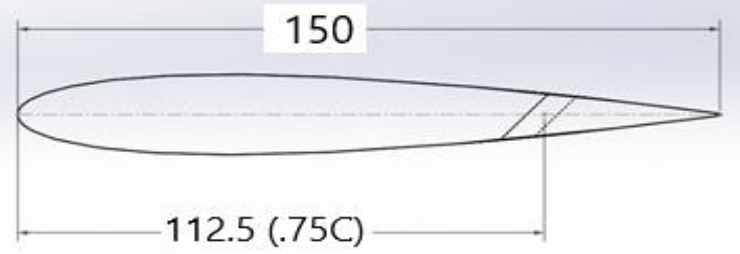

Fig. 3: 2D wireframe view of modified wing

Holes were made at $45^{\circ}$ with the chord line of the airfoil, which creates the same angle with the air flow direction of the wind tunnel at $0^{\circ}$ angle of attack. For instance the position of a hole at $75 \%$ of total chord length $(.75 \mathrm{C})$ is shown in Fig. 3. To connect the airfoil with the wind tunnel, a steel rod was attached with it.

Two Pitot tubes and a static port were mounted in the test section of the wind tunnel test section to measure the upstream and downstream velocities with the help of pressure transducers. The Versatile Data Acquisition System (VDAS) took the pressure readings from there and calculated the airspeed inside the test section. All the dimensions in the figures are at $\mathrm{mm}$.

\subsection{Experimental Setup:}

This experiment was performed in a low speed subsonic wind tunnel. The open circuit wind tunnel has a 300 $\mathrm{mm} \times 300 \mathrm{~mm}$ test section. The experiment was carried out in a range of Reynolds Number $1.03 \mathrm{e}^{5}$ to $2.58 \mathrm{e}^{5}$. Measurements were taken by using three component balance. Three component balance is a force measuring device shown in Fig. 4 where high quality load cells are used. When an airfoil exerts lift or drag force, wires connecting with these load cells are stretched which creates a small voltage in the load cell. This small voltage then processed, amplified and converted into actual force. A data acquisition system was in control to process the signal from load cells. The data acquisition system automatically turns the raw forces data into the form of lift and drag coefficient and shows them in a software interface.

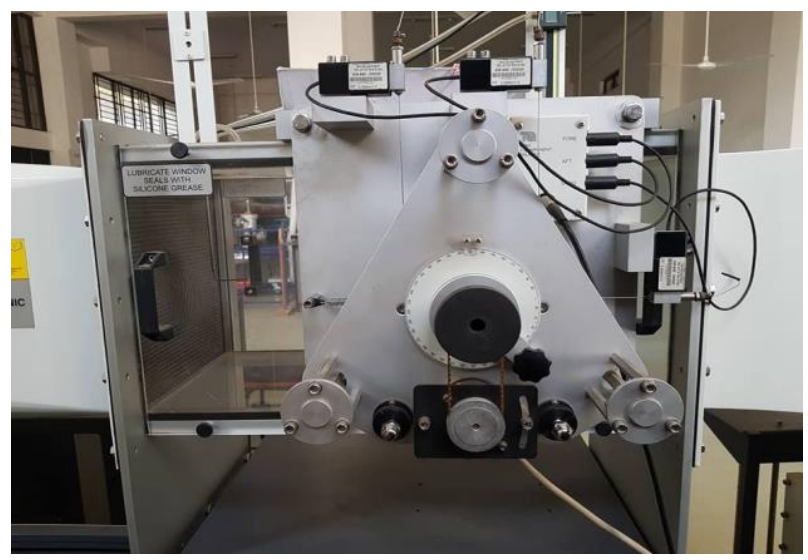

Fig. 4: Three Component Balance

The mean velocity was measured by a Pitot-static tube. Total pressure is measured by Pitot tube and static pressure or wall pressure is measured by suitable static pressure tap. VDAS uses the following equation to measure mean velocity [5],

Mean velocity, $\mathrm{V}=\sqrt{\frac{2\left(P_{0}-P_{1}\right)}{\rho}}$

Here, $P_{0}=$ Total Pressure

$P_{1}=$ Static Pressure

\section{COMPUTATIONAL METHOD}

For flow visualization and validation, numerical simulations were done on this problem.

\subsection{Turbulence Model:}

Unsteady incompressible numerical simulations were performed using a commercial Navier-Stokes solver called ANSYS 16.0 (FLUENT). This solver employs a finite volume method and the simulation can assume both laminar and turbulent flow. The simulations were using Spalart-Allmaras turbulence model. This model is economical for larger meshes and aerodynamics related problems. The transport equation for this model is.[6]

$$
\begin{aligned}
\frac{\partial}{\partial t}(\rho \tilde{v})+\frac{\partial}{\partial x_{i}}\left(\rho \tilde{v} u_{i}\right) \\
=G_{v} \\
+\frac{1}{\sigma_{\tilde{v}}}\left[\frac{\partial}{\partial x_{j}}\left\{(\mu+\rho \tilde{v}) \frac{\partial \tilde{v}}{\partial x_{j}}\right\}\right. \\
\left.+C_{b 2} \rho\left(\frac{\partial \tilde{v}}{\partial x_{j}}\right)^{2}\right]-Y_{v}+S_{\tilde{v}}
\end{aligned}
$$

\subsection{Meshing:}

For meshing, a rectangular domain was selected and then extruded with 0.3 meter of depth. Another small rectangle was extruded for creating region of influence. At the region of influence the element size was 0.03 meter.

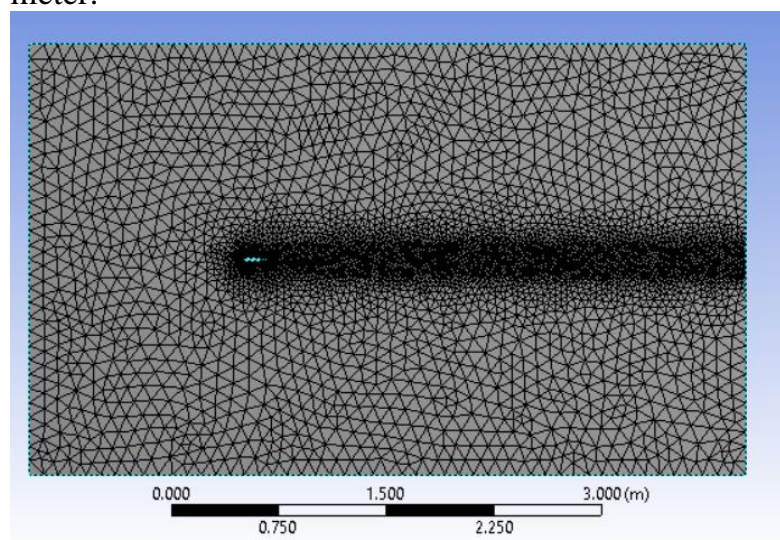

Fig. 5: 2D view of 3D meshing

At the surface of the airfoil, 15 inflation layers were created to capture the boundary layer. Growth rate for inflation layers was 1.2. The mesh had 593390 elements. 


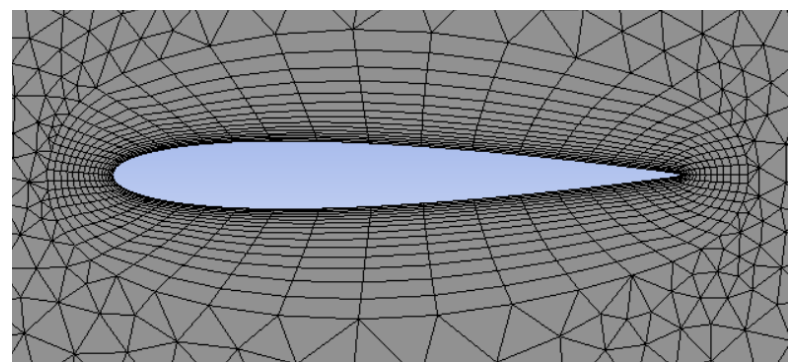

(a)

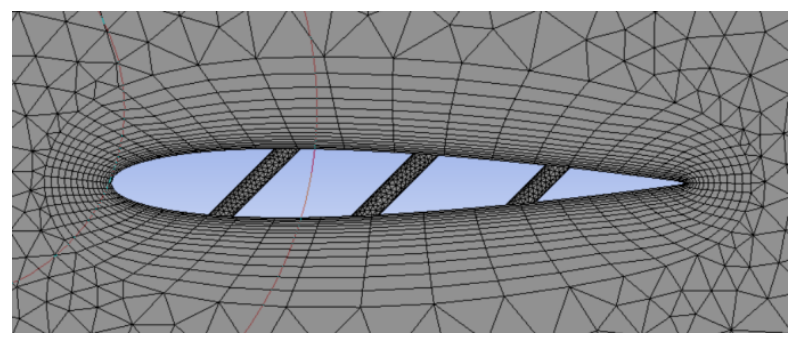

(b)

Fig. 6: Close view of mesh around airfoil (a) without holes, (b) without holes

\subsection{Numerical Validation:}

Results from numerical simulation need validation for which it is often compared with experimental results. In this case, lift coefficient of NACA 0012 airfoil obtained from both experimental and computational simulation were compared in Fig. 7.

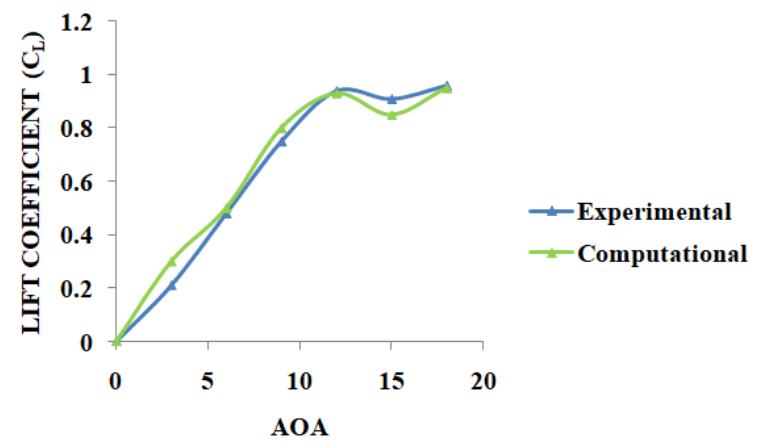

Fig. 7: Lift Coefficient vs AOA obtained from experiment and computational simulation.

From the figure, it is observed that both experimental and simulation results are similar and any differences between them are in acceptable region.

\section{RESULT \& DISCUSSION}

\subsection{Experimental Result:}

In This experiment, measurements of lift coefficient and drag coefficient were taken at different angle attacks for both the unmodified and modified airfoils. The measurements were taken from $0^{\circ}$ angle of attack to $20^{\circ}$ angle of attack with a $1^{\circ}$ interval. The experiment was carried out at four different Reynolds number $\left(1.03 \mathrm{e}^{5}\right.$, $\left.1.55 \mathrm{e}^{5}, 2.06 \mathrm{e}^{5}, 2.58 \mathrm{e}^{5}\right)$.

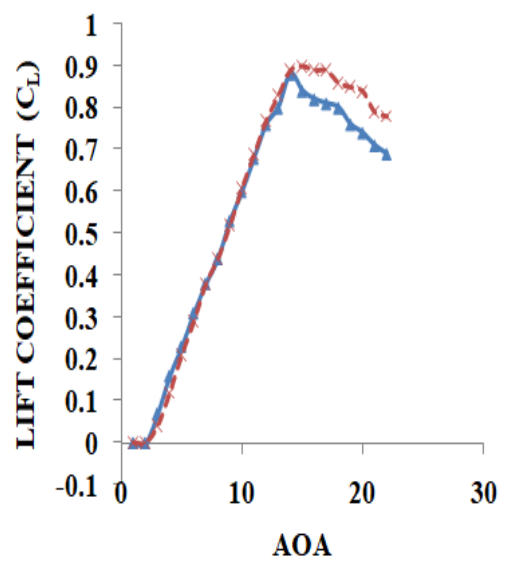

$\simeq$ Without Holes

$--x-$ With Holes

(a)

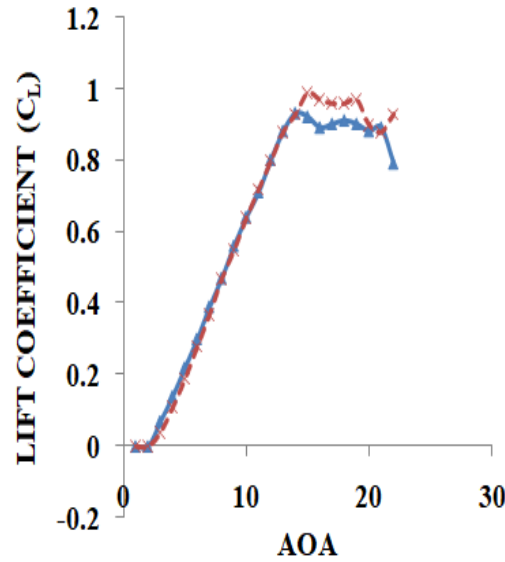

$\simeq$ Without Holes

---- -With Holes

(b)

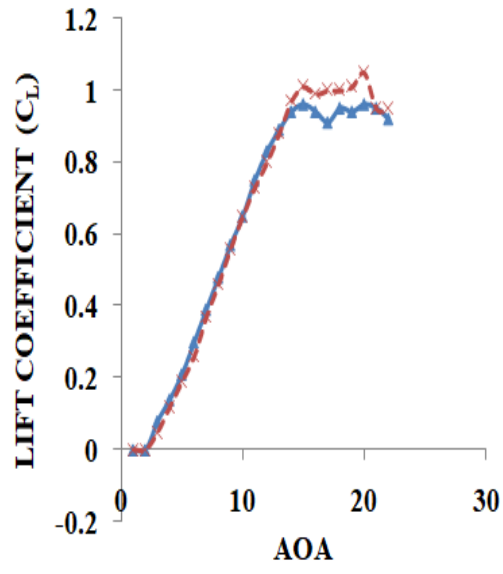

$\simeq$ Without Holes

---- With Holes

(c)

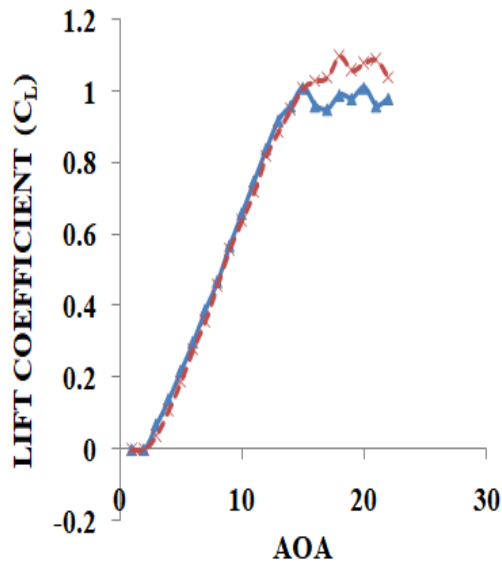

$\ldots$ Without Holes ---- -With Holes

(d)

Fig. 8: Lift Coefficient vs AOA at (a) Re $1.03 \mathrm{e}^{5}$

(b) $\operatorname{Re} 1.55 \mathrm{e}^{5}$ (c) $\operatorname{Re} 2.06 \mathrm{e}^{5}(\mathrm{~d}) \operatorname{Re} 2.58 \mathrm{e}^{5}$ 
After analyzing the graphs of Fig. 8, it was found out that lift coefficient for both plain airfoil and airfoil with distributed slanted holes have similar slope up to around $12^{\circ}$ angle of attack at all airspeeds. This means, up to $12^{\circ}$ both airfoils have almost similar lift coefficient. But at higher angle of attack, significant increment in coefficient of lift is observed for airfoil with slanted holes. In some of the cases, stall gets delayed for airfoil with slanted holes. For unmodified airfoil, the stall region stays in $11^{\circ}-14^{\circ}$ AOA. In case of airfoil with slanted holes, stall gets delayed by $1^{\circ}$ at $\operatorname{Re} 1.03 \mathrm{e}^{5}$ and $\operatorname{Re} 1.55 \mathrm{e}^{5}$, $2^{\circ}$ at $\operatorname{Re} 2.58 \mathrm{e}^{5}$. For airfoil with slanted holes flow gets reattached after stall region at higher flow speed.

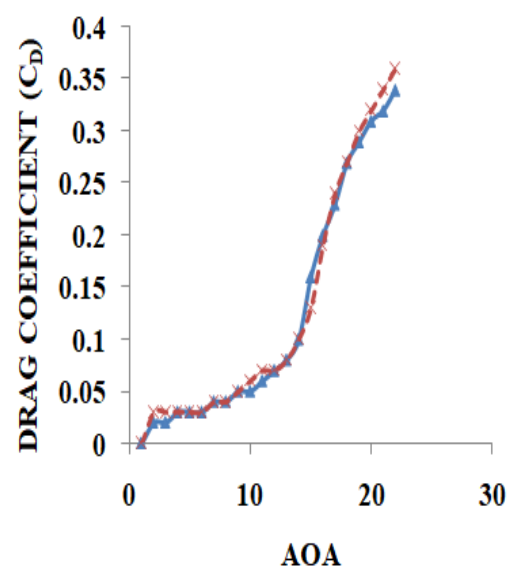

$\simeq$ Without Holes -----With Holes

(a)

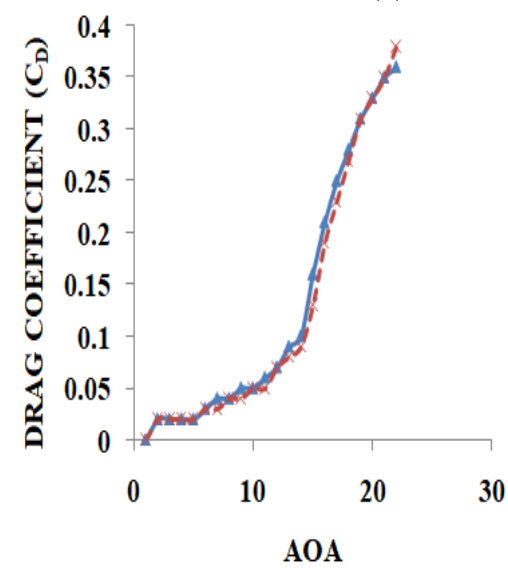

$\simeq$ Without Holes ---- With Holes

(b)

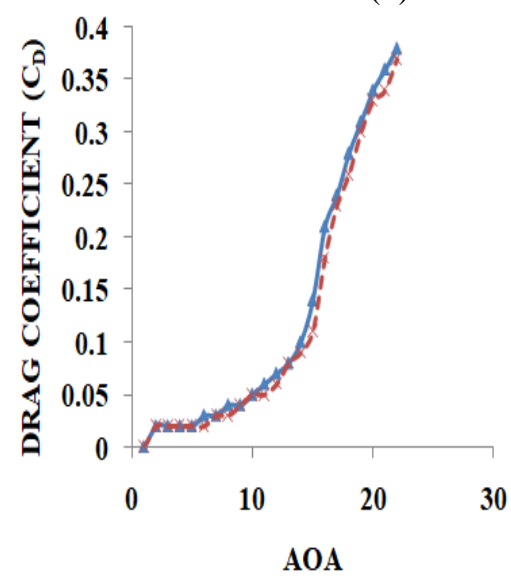

-Without Holes ---- With Holes

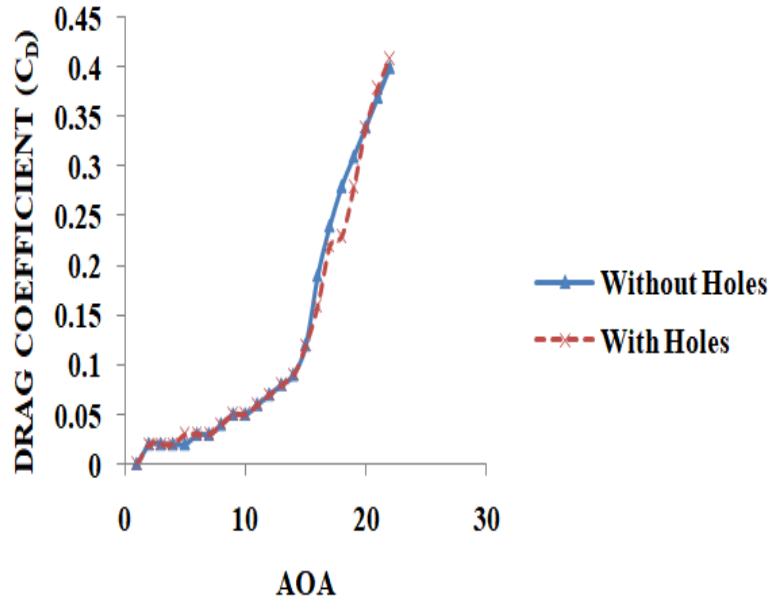

(d)

Fig. 9: Drag Coefficient vs AOA at (a) Re $1.03 \mathrm{e}^{5}$

(b) $\operatorname{Re} 1.55 \mathrm{e}^{5}$ (c) $\operatorname{Re} 2.06 \mathrm{e}^{5}$ (d) $\operatorname{Re} 2.58 \mathrm{e}^{5}$

The graphs of Fig. 9 express that drag coefficient remains almost the same for both the unmodified and modified airfoil at all Reynolds number.

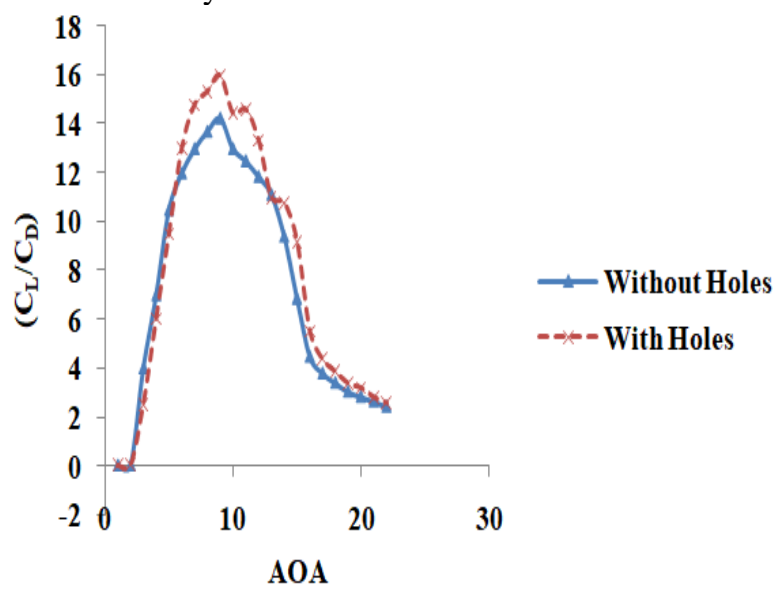

Fig. 10: $C_{L} / C_{D}$ vs $A O A$ at $\operatorname{Re} 2.06 \mathrm{e}^{5}$

As the drag coefficients of both the airfoils remain almost constant, but the coefficient of lift increases for higher angle of attack, the $C_{L} / C_{D}$ ratio increases on that range. For instance, the $C_{L} / C_{D}$ graph at Re $2.06 \mathrm{e}^{5}$ is shown in Fig. 10 where the increment is clearly visible. Thereby it is observed that the lift to drag ratio increases drastically in higher angle of attack (around $7^{\circ}$ to $15^{\circ}$ ) which is a positive sign of better aerodynamic performance and increment in overall efficiency in that region.

\subsection{Computational Result:}

Simulations of the unmodified and modified airfoil were done at $20 \mathrm{~m} / \mathrm{s}$ speed. From the simulations, lift and drag coefficients for both the airfoils were found out.

(c) 


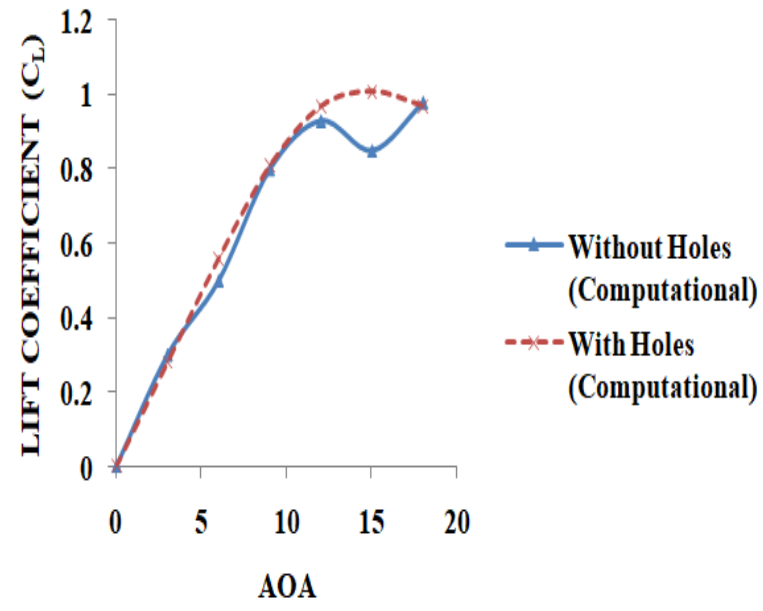

Fig. 11: Lift Coefficient vs AOA at $20 \mathrm{~m} / \mathrm{s}$ (Computational)

From Fig. 11, it is observed that lift coefficient increased at higher angle of attack just like the result obtained from the experimental result. It is also observed that stall angle is also delayed for both computational and experimental results.

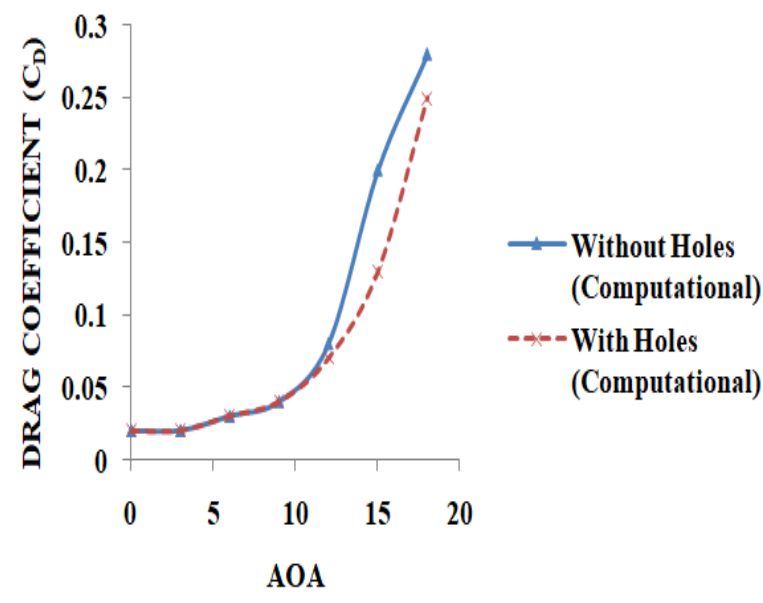

Fig. 12: Drag Coefficient vs AOA at $20 \mathrm{~m} / \mathrm{s}$ (Computational)

From the drag coefficient vs AOA graph (Fig. 12), it is also clear that drag coefficient reduced at higher angle of attack. Though in the experimental result, the reduction of drag coefficient was not that significant but this difference between experimental and computational result might be caused by two reasons. First of all, wooden prototypes of both the airfoils were hand manufactured, there was certain roughness and sharp edges which is responsible for increasing drag and thus the drag reduction in experimental setup is less noticeable. The second cause of this difference can be explained by the $\mathrm{Y}^{+}$value. As $\mathrm{Y}^{+}$in numerical simulation denotes the height of the first cell from the surface, it is important to make this value less than 1 to capture the boundary layer. But in reality this value remains in 30 to 300 for less computational power. So sometimes the drag coefficient obtained from numerical simulation is little bit off from the real value. These two reasons may affect the differences between experimental result and computational result. But in both the cases reduction of drag coefficient at higher angle of attack is noticed which eventually increases the overall all aerodynamic efficiency at higher angle of attack.

\subsection{Velocity Contour:}

From the post processing part of ANSYS FLUENT, velocity contour for both the airfoil was obtained. This is a great technique to visualize the flow field around an airfoil. For better resolution velocity contour at $15^{\circ} \mathrm{AOA}$ was chosen.

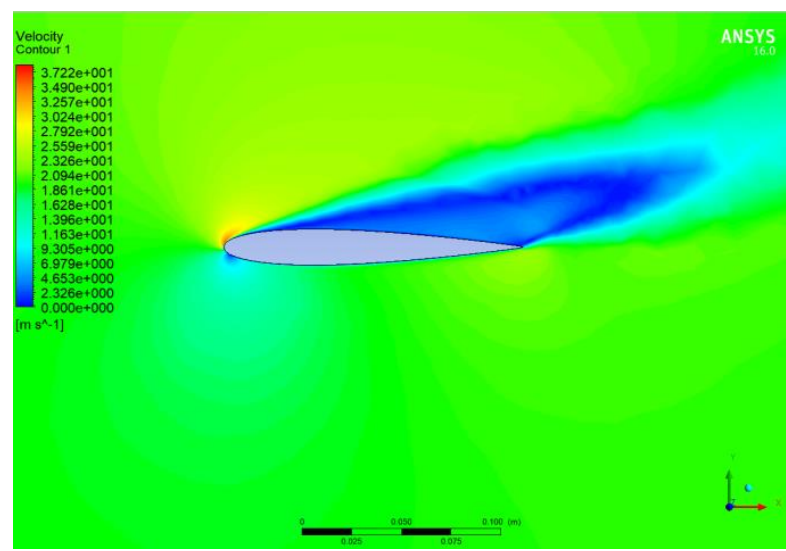

(a)

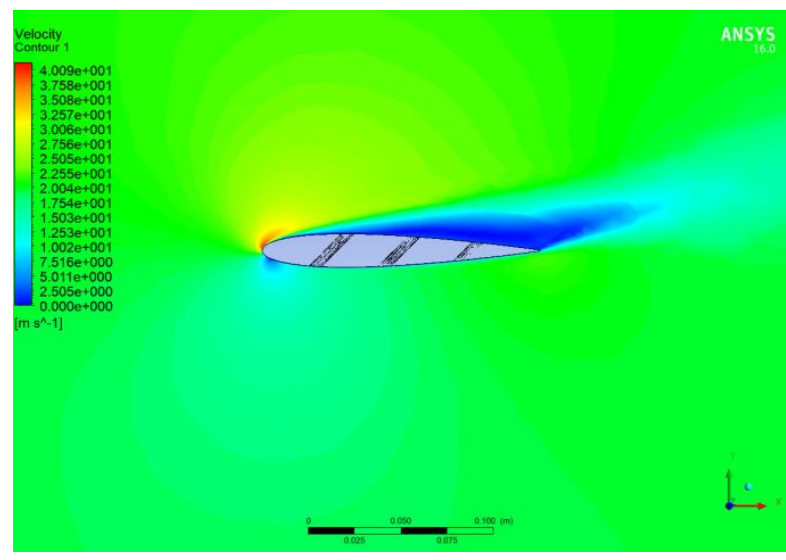

(b)

Fig. 13: Velocity contour at $15^{\circ} \mathrm{AOA}$ for (a) airfoil without holes, (b) airfoil with holes

Blue region in the velocity contour shows the vacuum created by the flow separation thus decreasing lift and increasing drag. Comparing these two velocity contours, it is clear that airfoil with slanted drills delayed and decreased the separation region compared to the airfoil without any modification. By doing this it increased the lift and reduced drag.

\section{CONCLUSION}

This Study reveals that, incorporating distributed slanted holes on NACA 0012 airfoil delay the stall little bit and also increases the lift coefficient at higher angle of attack which is clearly visible in both experimental and computational simulations. The lift coefficient remains almost the same up to $12^{\circ}$ angle of attack.

The drag coefficient remains almost the same for both types of airfoil. Though at higher angle of attacks, reduction of drag coefficient is not that significant, the computational simulation reveals something fruitful. Reduction of drag coefficient at higher angle of attack (above $12^{\circ}$ ) is noticed in the CFD simulation which concludes that at higher angle of attack slanted holes on airfoil improve the overall aerodynamic performance. Such airfoils may be useful to manufacture car spoilers, wind turbine blades and many other places. 
Further studies can be carried out to identify the optimal number of holes, their ideal positions and the appropriate slanting angle. Also most suitable airfoil type can be found which provides the best possible output with this modification.

\section{REFERENCES}

[1] Y. Xie, J. Chen, H. Qu, G. Xie, D. Zhang, and M. Moshfeghi, "Numerical and experimental investigation on the flow separation control of S809 airfoil with slot," Math. Probl. Eng., vol. 2013, 2013.

[2] Z. Ni, M. Dhanak, and T. Chow Su, "Performance characteristics of airfoils with leading-edge tubercles and an internal slot," AIAA J., vol. 57, no. 6, pp. 2394-2407, 2019.

[3] C. K. Sumesh and T. J. Sarvoththama Jothi, "Aerodynamic noise characteristics of a thin airfoil with line distribution of holes adjacent to the trailing edge," Int. J. Aeroacoustics, vol. 18, no. 4-5, pp. 496-516, 2019.

[4] C. Wong and K. Kontis, "Flow control by spanwise blowing on a NACA 0012," J. Aircr., vol. 44, no. 1, pp. 337-340, 2007.

[5] A. J. D., Fundamentals of aerodynamics, Fifth Edit. New York: McGraw-Hill, 1984.

[6] ANSYS Fluent Theory Guide, ANSYS Inc. 